\begin{tabular}{c|l|l|l}
$\begin{array}{c}\text { Cose Reports in } \\
\text { Onduly }\end{array}$ & $\begin{array}{l}\text { Case Rep Oncol 2010;3:9-13 } \\
\text { Dol: } 10.1159 / 000271596\end{array}$ & & $\begin{array}{l}\text { Published online: January 12, 2010 S. Karger AG, Basel } \\
\text { ISSN 1662-6575 } \\
\text { www.karger.com/cro }\end{array}$ \\
\hline
\end{tabular}

\title{
Sarcoidosis Presenting as an Intraperitoneal Mass
}

\author{
John V. Brown III ${ }^{a} \quad$ Howard D. Epstein ${ }^{b} \quad$ Miles Chang ${ }^{c}$ \\ Bram H. Goldstein ${ }^{a}$ \\ aGynecologic Oncology Associates, Hoag Memorial Hospital Presbyterian, \\ Departments of ${ }^{b}$ Pathology and 'Radiology, Newport Beach, Calif., USA
}

\section{Key Words}

Sarcoidosis · Intraperitoneal · Gynecologic oncology · Diagnosis

\begin{abstract}
Background: Sarcoidosis is an idiopathic, inflammatory condition primarily encountered within the lungs but very rarely identified in the peritoneum.

Case Study: A 34-year-old woman presented with pleural effusion, ascites and an adnexal mass, indicative of ovarian cancer.

Results: A biopsy revealed granulomas and lymphocytic infiltrate, consistent with sarcoidosis. The patient's symptoms were resolved with corticosteroids. However, 2 years later, she developed another pelvic mass and underwent a diagnostic laparoscopy. Final pathology revealed granulomas and endometriosis, consistent with sarcoidosis.

Conclusion: Since intraperitoneal sarcoidosis is extremely rare, the differential diagnosis is unlikely to include this condition in the context of presumptive ovarian cancer. However, in patients with a history of sarcoidosis, physicians should maintain a high index of suspicion to effectuate early detection and provide appropriate treatment.
\end{abstract}

\section{Introduction}

Sarcoidosis is a chronic, multi-system disease that is associated with profuse granulomatous lesions and inflammation [1]. The cause of sarcoidosis is undetermined, although the condition may be related to a bacterial or fungal infection or an immune response from an unidentified antigen [1-3]. The onset of sarcoidosis may be spontaneous or gradual, and patients can either be asymptomatic or exhibit a varying clinical presentation $[1,2,4]$.

Sarcoidosis has been rarely identified in the peritoneal region $[5,6]$. Consequently, the disease would unlikely be included in the differential diagnosis of a pelvic mass and ascites, potentially resulting in a delayed diagnosis and inappropriate treatment $[1,4,7]$. 


\begin{tabular}{|c|c|c|c|}
\hline $\begin{array}{l}\text { Cose Reports in } \\
\text { inceayly }\end{array}$ & $\begin{array}{l}\text { Case Rep Oncol 2010;3:9-13 } \\
\text { D0l: } 10.1159 / 000271596\end{array}$ & Published online: January 12, 2010 & \begin{tabular}{|l} 
( ) 2010 S. Karger AG, Basel \\
ISSN $1662-6575$ \\
www.karger.com/cro
\end{tabular} \\
\hline
\end{tabular}

\section{Case Report}

A 33-year-old Caucasian, nulligravida patient initially presented with pleural effusion, ascites, and a left adnexal mass in August 2007. Her CA-125 level was $230 \mathrm{U} / \mathrm{ml}$ but clinically, she was asymptomatic. The patient underwent a diagnostic laparoscopy, which revealed several, diffuse peritoneal nodules. Initially, a presumptive diagnosis of small, bilateral hydrosalpinges was made. The ovaries were diffusely embedded within the disease process. Approximately $70 \mathrm{ml}$ of straw-colored fluid was identified in the pelvis and left upper quadrant. The ascites was aspirated and submitted for cytologic examination. Moreover, sections of the right lower quadrant abdominal wall were biopsied to rule out malignancy (fig. 1).

The differential diagnosis included tuberculosis, sarcoidosis or an unusual infection. Final pathologic evaluation revealed sarcoidosis. The patient was referred to pulmonary medicine and started on corticosteroid therapy, whereupon her condition improved dramatically.

During the patient's follow-up examination in May 2009, a 9-cm pelvic mass was detected (fig. 2), although she remained asymptomatic. Her CA-125 was $128 \mathrm{U} / \mathrm{ml}$. A diagnostic laparoscopy was performed to determine if the cystic structure could be removed laparoscopically, particularly since recurrent sarcoidosis was the presumed etiology.

A variety of options were explained preoperatively, but the family's preference was conservative (i.e., fertility retention) management. However, due to the magnitude of disease, the prospect of a hysterectomy was also comprehensively discussed.

The mass was cystic, containing a light brown-colored fluid. Culture and sensitivity testing was obtained. Consequently, a hysterectomy with bilateral salpingo-oophorectomy was again considered, but after an intraoperative discussion was held with the patient's family, we continued with conservative management. The mass was excised with the exception of an approximately $3.5 \mathrm{~cm} \times 3.5 \mathrm{~cm}$ plaque, which could not be removed without excising the ovaries.

Frozen section revealed endometriosis, granulomatous inflammation and focal necrosis, with no evidence of malignancy (fig. 3). The findings were consistent with sarcoidosis. Currently, the patient is doing well with 5 months of follow-up and is followed by the departments of gynecologic oncology and pulmonary medicine.

\section{Conclusion}

Sarcoidosis or Boeck's sarcoid was initially documented in the late 19th century by Hutchinson, where he described a patient who presented with numerous purple lesions afflicting both the face and upper extremities [7]. Robinson et al. documented one of the earliest reports of a patient with peritoneal sarcoidosis [6]. More recently, Ngô et al. reported on a patient who developed sclerosing peritonitis in conjunction with exudative ascites [5]. The patient was subsequently treated with corticosteroid therapy and she has remained symptom-free.

The present case of peritoneal sarcoidosis was very unusual in that following treatment and symptom resolution, the disease returned in an ostensibly more fulminant form. Furthermore, it was noteworthy that the condition coincided with endometriosis, especially since studies have suggested that autoimmunity is involved in the development of endometriosis [3].

Peritoneal sarcoidosis is a very rare condition that can be misinterpreted as metastatic disease or endometriosis and, thus, oncology physicians may be less likely to diagnose the condition forthwith, potentially confounding appropriate management $[1,4,7]$. An elevated CA-125 has been reported in connection with sarcoidosis and should be considered in determining the diagnosis [7]. Moreover, the exclusion of peritoneal tuberculosis is essential, even in the context of a negative PPD because the disease is nonspecific and may coincide with immunosuppression [8]. When ascites manifests with 


\begin{tabular}{c|l|l|l}
$\begin{array}{c}\text { Case Reports in } \\
\text { Onda.jy }\end{array}$ & $\begin{array}{l}\text { Case Rep Oncol 2010;3:9-13 } \\
\text { Dol: } 10.1159 / 000271596\end{array}$ & & $\begin{array}{l}\text { Published online: January 12, 2010 } \\
\text { ISSN 1662-6575 } \\
\text { www.karger.com/cro }\end{array}$ \\
\hline
\end{tabular}

peritoneal sarcoidosis, the fluid is predominantly lymphocytic. Additionally, since the small, grayish-white granulomatous nodules in the peritoneum and omentum are often undetected on CT, surgery is usually necessary to ascertain the extent of disease involvement [2].

\section{Acknowledgement}

This study was funded by a grant from the Women's Cancer Research Foundation.

Fig. 1. The 2007 biopsy demonstrates noncaseating granulomata, characteristic of sarcoidosis. Sarcoidosis is a diagnosis of exclusion as the finding of granulomata, whether caseating or noncaseating, should result in a clinical and pathologic search for infectious disease, primarily from acid fast bacilli and fungi $(200 \times)$.

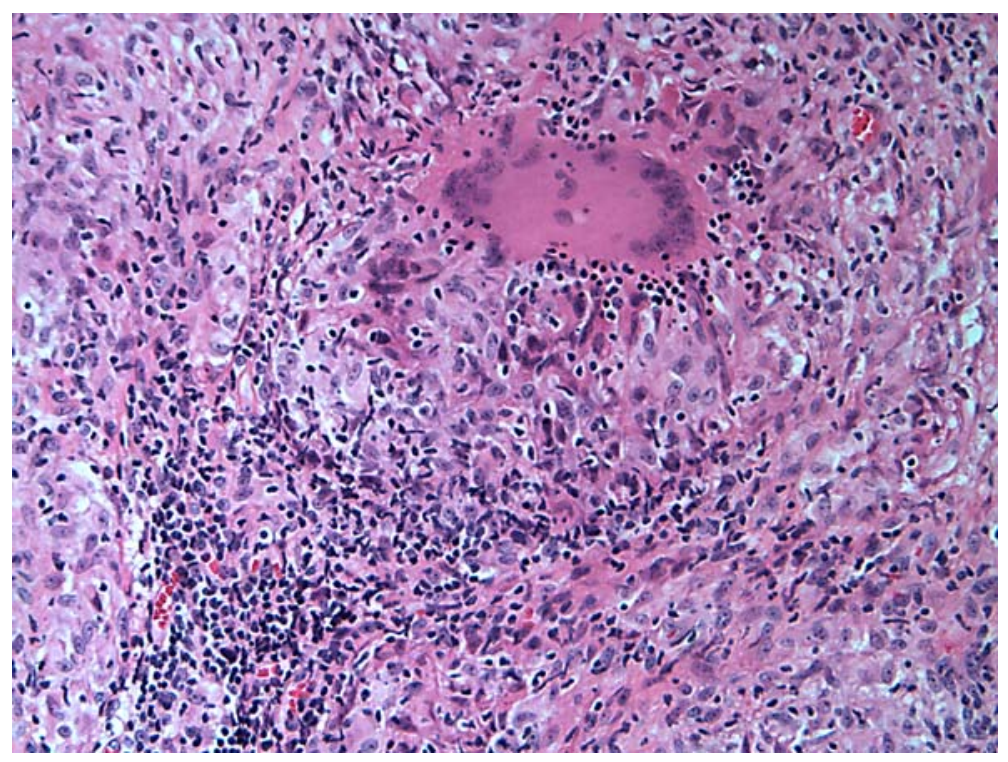




\begin{tabular}{c|l|l|l}
$\begin{array}{c}\text { Case Reports in } \\
\text { Ondolady }\end{array}$ & $\begin{array}{l}\text { Case Rep Oncol 2010;3:9-13 } \\
\text { D0I: 10.1159/000271596 }\end{array}$ & Published online: January 12, 2010 & $\begin{array}{l}\text { O 2010 S. Karger AG, Basel } \\
\text { ISSN 1662-6575 } \\
\text { www.karger.com/cro }\end{array}$ \\
\hline
\end{tabular}

Fig. 2. A large, complex cystic lesion is noted in the anterior pelvis, displacing the uterus posteriorly.

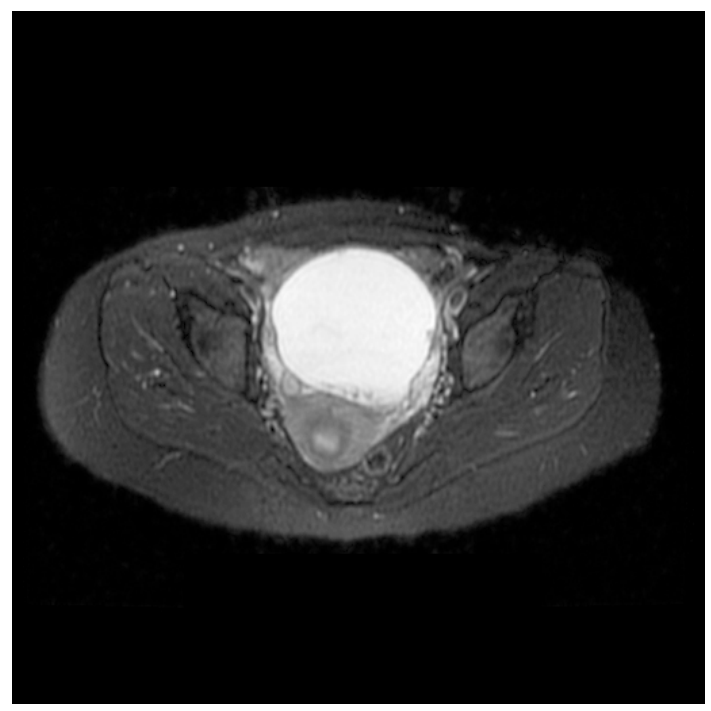

Fig. 3. The 2009 biopsy shows endometriosis and sarcoid commingling. The pathologic stains were negative for AFB and fungi $(400 \times)$.

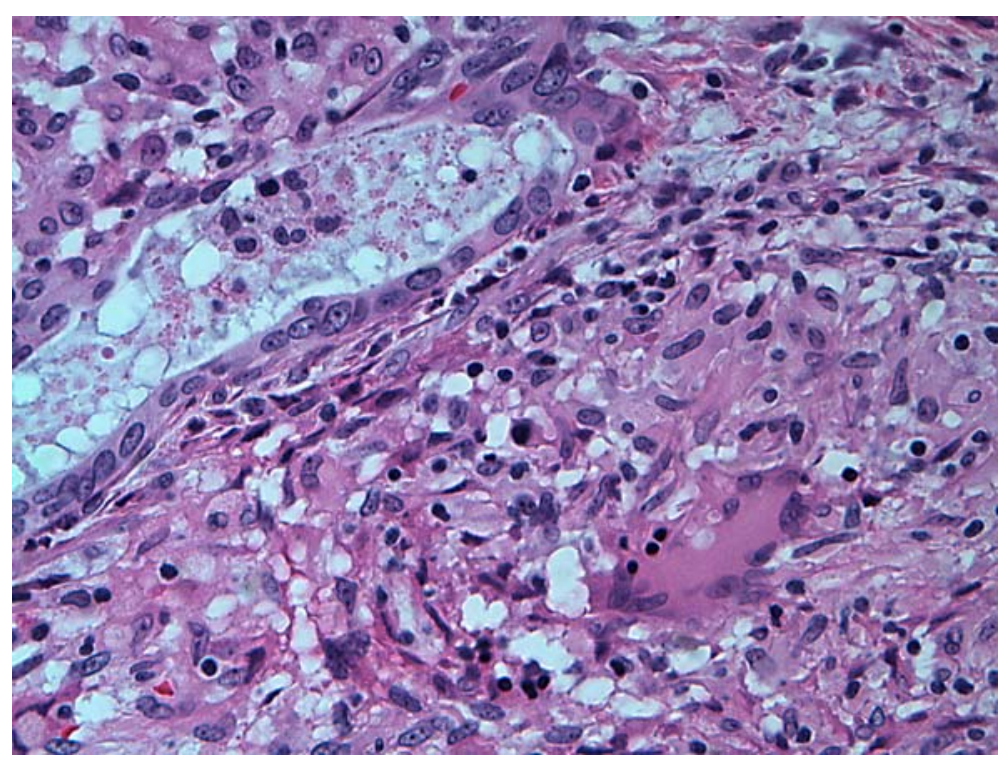




\section{References}

1 Powell JL, Cunill ES, Gajewski WH, Novotny DB: Sarcoidosis mimicking recurrent endometrial cancer. Gynecol Oncol 2005;99:770-773.

2 Iyer S, Afshar K, Sharma OP: Peritoneal and pleural sarcoidosis: an unusual association - review and clinical report. Curr Opin Pulm Med 2008;14:481-487.

-3 Gajbhiye R, Suryawanshi A, Khan S, Meherji P, Warty N, Raut V, et al: Multiple endometrial antigens are targeted in autoimmune endometriosis. Reprod Biomed Online 2008;16:817-824.

4 Goldstein BH, Rettenmaier MA, Sheffer EC, Chan K, Birk C, Brown JV, Micha JP: Sarcoidosis imitating metastatic cervical cancer. Arch Gynecol Obstet 2008;277:441-443.

5 Ngô Y, Messing B, Marteau P, Nouël O, Pasquiou A, Lavergne A, et al: Peritoneal sarcoidosis. An unrecognized cause of sclerosing peritonitis. Int J Surg Pathol 2009;17:219-230.

6 Robinson EK, Ernst RW: Boeck's sarcoid of the peritoneal cavity; a case report. Surgery 1954;36:986-991.

7 Fuchs F, Le Tohic A, Raynal P, Guillot E, Chis C, Meckenstock R, et al: Ovarian and peritoneal sarcoidosis mimicking an ovarian cancer. Gynecol Obstet Fertil 2007;35:41-44.

8 Rasheed S, Zinicola R, Watson D: Intra-abdominal and gastrointestinal tuberculosis. Colorectal Dis 2007;9:773-783. 